BLS 32, No 1 2006. DOI: http://dx.doi.org/10.3765/bls.v32i1.3445 (published by the Berkeley Linguistics Society and the Linguistic Society of America)

\title{
On Non-Optimal Laryngeal Timing: The Case of Trique
}

\author{
CHRISTIAN DICANIO \\ University of California, Berkeley
}

\section{Introduction}

A central issue in linguistics has been the degree of independence and interdependence between phonetics and phonology. Recent phonological research has looked at the phonetic domain for answers to phonological questions and viceversa. Out of this research two main perspectives have arisen: the integrated approach and the modular approach (Howe and Pulleyblank 2001). The former view assumes that phonological units are arranged in such a way so as to take advantage of positions in the word which are perceptually salient (Silverman 1997a, Steriade 2001, Hayes and Steriade 2004). This view assumes that phonetic details like articulatory timing and perception are encoded directly into the phonology of a language. The phonology chooses the phonetically optimal environment where the contrast appears. By contrast, the modular view (Howe and Pulleyblank 2001) proposes that the distribution of segments is governed only by the language's phonology, while the details of articulatory timing and perception are controlled by the language-particular phonetics. The phonology is therefore insensitive to optimal phonetic environments. Research on laryngealization and laryngeal timing has characterized the work supporting the integrated view (Silverman 1997a, 1997b, Blankenship 2002). Research on languages with laryngealization and laryngeal contrasts, therefore, are strong candidates for supporting one approach over the other. Trique is one such language.

San Martín Itunyoso Trique (henceforth Itunyoso Trique) is a Mixtecan (Otomanguean) language spoken by approximately 2,500 people in Oaxaca, Mexico and the topic of this author's fieldwork. The language contains a large tonal inventory and set of laryngeal contrasts. In this paper I will argue that these contrasts are best understood along the modular approach outlined above. The distribution of tone and laryngeals as well as their phonetics are non-optimizing, given claims made by Silverman (1997a) and Steriade (2001). The non-optimality of these contrasts coincides with the account given by Howe and Pulleyblank (2001) where the exceptional phonological distribution of laryngeal segments is prosodically-licensed. 


\section{Christian DiCanio}

\section{On Optimal Contexts for Laryngealization}

In his dissertation, Silverman (1997a) argues that laryngeals tend to occur in environments where they may be optimally perceived. For instance, the optimal environment for both [h] and [?] is at the release of an onset stop. ${ }^{1}$ He states that "when the (nonmodal phonation) [h, ?] stand in isolation prevocalically, or especially if aspiration/creak is realized at prevocalic stop release, this sudden onset of energy helps to better cue the noise associated with glottal spreading" (Silverman 1997b:251). This initial context is preferable to final contexts, where the cues to glottal spreading are not as robust. Thus, he observes that onset glottalization and aspiration are preferable to coda glottalization and aspiration. This observation is confirmed within a typology of languages. For instance, it is much more common to find ejectives in word-initial position or intervocalically than to find them at word-final position or pre-consonantally. It is also much more common to find languages with post-aspirated stops than with pre-aspirated stops. In both these contexts, laryngealization is timed with the onset release.

In tone languages, laryngeals are also timed to occur in initial position. Silverman states that "prevocalic nonmodal phonation followed by modal phonation is the optimal timing pattern, cueing vocalism, voicelessness, glottal closure, and tone" (Silverman 1997b:256). In other words, if we have a tone language with laryngeals, the laryngeal ideally occurs pre-vocalically. The explanation for this laryngeal-tone phasing is that tonal contrasts are optimally perceived during periods of modal phonation. Since laryngeals alter F0, the primary correlate of tonal contrasts, they are timed so that they precede the tonal contrast which occurs on the modal portion of the vowel. Laryngeals are sequenced so that there is a maximum perceptibility of tone. Tone is recoverable in the environment of a laryngeal only when it can be staggered. Such constraints on the distribution and timing of laryngeals are encoded directly into the language's phonology. Such a model of tonal-laryngeal timing is only valid, though, if it can be tested against solid empirical data.

\section{Trique Phonology}

Itunyoso Trique has a complex set of tone and laryngeal contrasts, including 9 tones, glottal consonants [h, $\mathrm{h}$, and pre-glottalized sonorants. As a language which contains both laryngeals and many tones, it serves as a fertile testing ground for Silverman's hypothesis. In particular, the distribution of laryngeals and their phonetic realization in Itunyoso Trique do not support a perspective where laryngeal segments are phased so as to avoid tonal overlap. Rather, they are best understood via the language's prosody, which determines a large set of the phonological contrasts that surface.

Many of the phonological contrasts in Itunyoso are only realized in root-final position. Therefore, it is not possible to talk about the distribution of phonemes or

\footnotetext{
1 The optimal context for laryngealization with sonorants is for them to be pre-glottalized (Silverman 1997a, Howe and Pulleyblank 2001).
} 


\section{On Non-Optimal Laryngeal Timing: The Case of Trique}

tone in Trique without first regarding the prosodic structure of roots in the language. ${ }^{2}$ There is some debate on the prosodic units of words in Mixtecan languages (Hinton 1992, Macaulay and Salmons 1995). This debate revolves around the question of where to place glottalization in the phonology of the language: as a feature of the root, the foot, or the syllable. In Itunyoso Trique, all laryngeals are restricted to the final syllable of the root, which may contain up to two laryngeal segments, a fact which is mirrored in Copala Trique (Hollenbach 1984). With the exception of laryngeal codas, syllables are always open. Final syllables without a laryngeal have a longer duration than non-final syllables. A table with most of the possible syllable types is given in (1).

(1) Itunyoso Trique Syllable Type Inventory

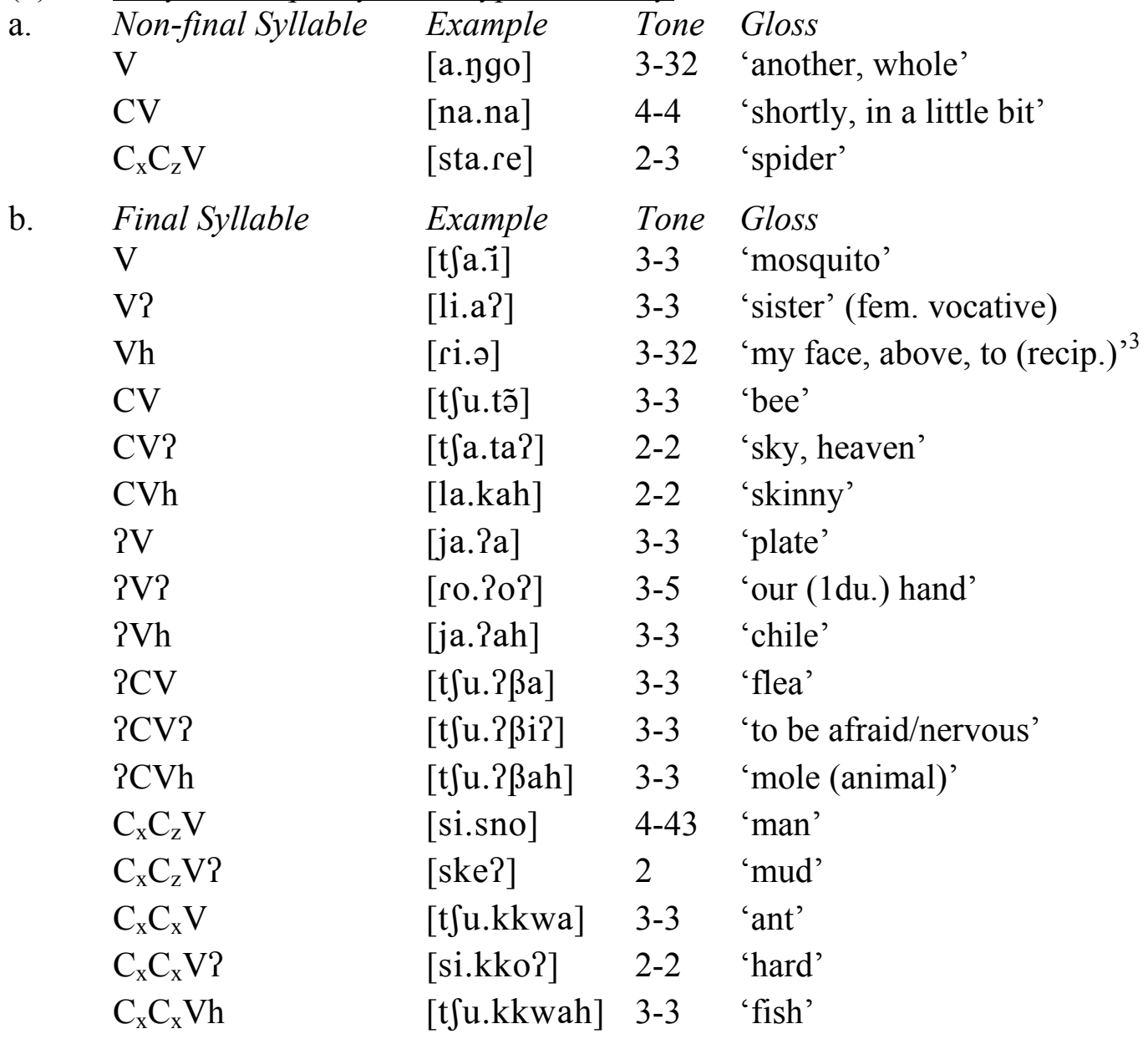

${ }^{2}$ All nominal or verbal roots may take one of 22 person-marking enclitics as a suffix to mark either possession or argument structure. The phonological licensing restrictions applying to roots do not apply to morphologically complex words.

3 All two vowel sequences are realized as separate monophthongal vowels. This is shown by syllable-final lengthening, which affects only the final vowel of the sequence, not a larger, diphthongal unit. 


\section{Christian DiCanio}

As we can see from the table above, the syllable-type inventory is unevenly distributed in Itunyoso Trique. The geminate-singleton ("fortis-lenis") consonant contrast and all laryngeals are restricted to root-final syllables. Laryngealized sonorants occur intervocalically, but only occur in initial position on monosyllabic words. Glottal stops occur intervocalically as root-final syllable onsets and as final-syllable codas. The glottal fricative occurs only as a coda in root-final syllables.

At first glance, the distribution of glottal stops and glottalized sonorants seems to fit within Silverman's predictions. He correctly predicts that the presence of final glottalization implicates initial glottalization. Since initial position is the best locus for non-modal phonation, languages favor glottalized onsets over glottalized codas, for reasons described in $\S 2$. However, the restriction of $/ \mathrm{h} /$ to root-final coda position is unusual, as languages with coda [h] almost always have an onset [h]. This distribution does not seem to correspond to Silverman's prediction on the distribution of laryngeal segments.

In addition to laryngeals, Itunyoso Trique contrasts 9 tones. ${ }^{4}$ Similar to the syllable distribution shown in (1), all of these tones occur on root-final open syllables, but only three $(/ 2 /, / 3 /, / 4 /)$ occur contrastively in non-final syllables. ${ }^{5}$ The distribution of tone in the language is given in (2).

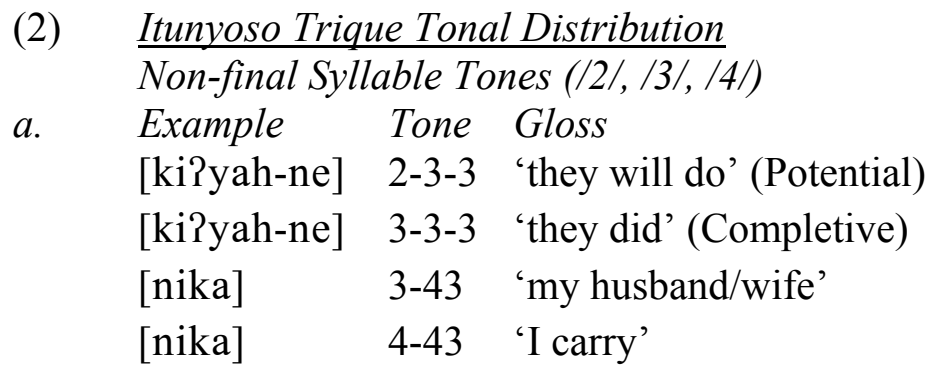

Final Syllable Tones (/1/, /2/, /3/, /4/, /5/, /43/, /32/, /31/, /13/)

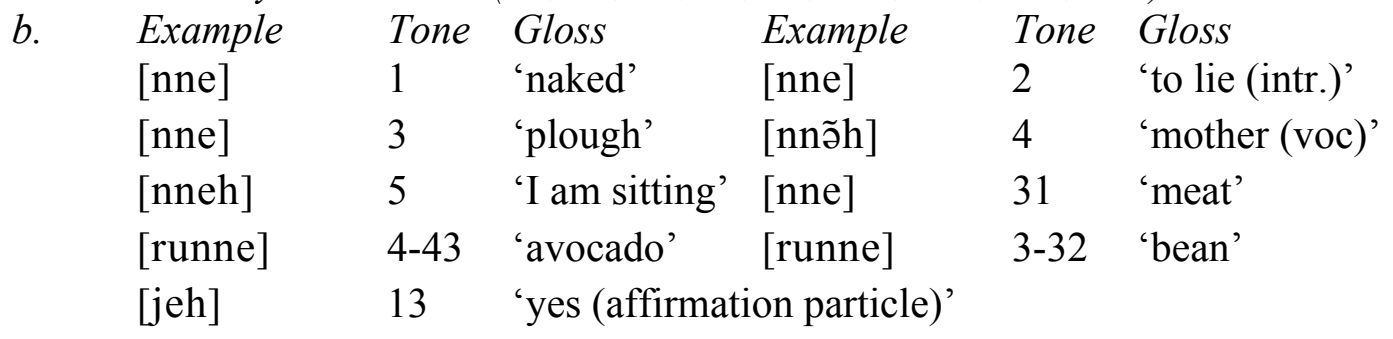

Many of the tones in (2) occur freely with laryngeal segments, but there are a few

\footnotetext{
$4 / 1 /$ is low, $/ 5 /$ is high

5 Tones $/ 1 /, / 5 /, / 43 /, / 32 /, / 31 /$, and $/ 13 /$ are assigned to the root-final syllable and then spread leftward via a process of tonal association, yielding disyllabic patterns like /1.1/ or /4.43/. For a similar account of this process in Copala Trique, see Hollenbach (1984).
} 
exceptions. First, contour tones do not occur with coda [?]. This restriction probably has to do with the vowel shortening that occurs before laryngeal codas, as contour tones tend to occur on vowels of longer duration (Zhang 2001). Second, tone $/ 5 /$ occurs only with a coda $[\mathrm{h}]$. This fact has to do with the origin of the $5^{\text {th }}$ tone in Trique, arising from $* / 4 /+\mathrm{h}$ (Longacre 1957, Hollenbach 1984). However, in Itunyoso Trique there are contexts where $/ 4 /$ surfaces with a coda $/ \mathrm{h} /$ synchronically, which is not the case in Copala Trique. Finally, no falling tone occurs with a coda $[\mathrm{h}]$. A table showing these restrictions is given in (3).

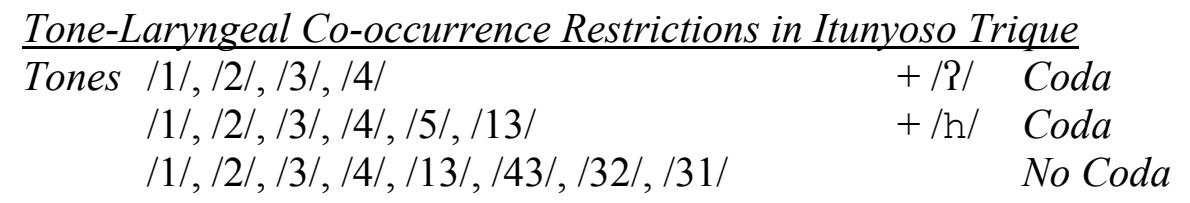

In Itunyoso Trique, many different tonal combinations may occur across an intervocalic glottal stop, without many exceptions. The only exception seems to be that tone $/ 3.5 /$ must occur with a coda $/ \mathrm{h} /$, as mentioned previously. This distribution is shown in (4).

\begin{tabular}{|c|c|c|c|c|c|c|}
\hline \multirow[t]{5}{*}{ a. } & \multicolumn{6}{|c|}{$V . P V h$} \\
\hline & $\begin{array}{l}\text { Tone } \\
1.1\end{array}$ & $\begin{array}{l}\text { Example } \\
\text { [na.Pah] }\end{array}$ & $\begin{array}{l}\text { Gloss } \\
\text { 'shame' }\end{array}$ & $\begin{array}{l}\text { Tone } \\
2.2\end{array}$ & $\begin{array}{l}\text { Example } \\
\text { [sñ.?ว̃h] }\end{array}$ & $\begin{array}{l}\text { Gloss } \\
\text { 'liar' }\end{array}$ \\
\hline & 3.3 & [snã.1ว̃h] & 'language' & 3.2 & [ju.?uh] & 'hole' \\
\hline & 4.4 & [jã.1ว̃h] & 'guitar' & 1.3 & [ũ.?ũh] & 'five' \\
\hline & 4.3 & [ne.?eh] & 'hiccups' & 3.5 & [jo.?oh] & 'land' \\
\hline
\end{tabular}

b. $\quad$ V.PV

\begin{tabular}{|c|c|c|c|c|c|}
\hline Tone & Example & Gloss & & & \\
\hline 1.1 & [kano.?o] & 'to wait' & 2.2 & [kã.Pã] & 'I go' \\
\hline 2.3 & {$\left[\mathrm{t} \int \mathrm{e} . \mathrm{Re}\right]$} & 'long' & 3.32 & [jã.१ว̃] & 'light' \\
\hline 3.3 & [jã.१ว̃] & 'god' & 3.1 & [kõ.?ã] & 'flu' \\
\hline 3.4 & [kə̃.Pə] & 'went (3sg)' & 4.43 & [kõ.?ã] & 'I went' \\
\hline 4.4 & [kano.?o] & 'medicine, $\mathrm{r}$ & ledy' & & \\
\hline 1.3 & [kã.ใว̃] & 'four' & & & \\
\hline
\end{tabular}

The fact that there are few restrictions on the distribution of tone with glottalization in Trique suggests that their distribution is not governed by any principles involving perceptual adequacy. What then is governing the distribution of tone and laryngeals? The distribution of these two phenomena is properly accounted given the phonotactic restrictions in the language, where root-final syllables are prominent. We have observed that a large set of tonal contrasts and laryngeal 


\section{Christian DiCanio}

contrasts (among other things) are limited to root-final syllables. Howe and Pulleyblank (2001) argue that the distribution of glottalized sonorants in Kashaya is governed in the same way. In Kashaya, glottalized sonorants only occur in coda position and are post-glottalized. The timing of glottalization and its distribution in the language is non-optimal given Steriade's (2001) and Silverman's (1997a) predictions, as the ideal location for glottalized sonorants is intervocalic, where they should be pre-glottalized. While these glottalized sonorants appear exceptional, they are easily explained by the fact that Kashaya has weight-by-position, demonstrated by stress patterns, closed-syllable shortening, and compensatory lengthening (Buckley 1994, 1995; cited in Howe and Pulleyblank 2001). The glottalized sonorants in Kashaya are moraically-licensed. In Itunyoso Trique, the restriction of laryngeals to word-final syllables, and the quirky distribution of $/ \mathrm{h} /$ to root-final coda position are easily explained given a root-final prosodic prominence that can license them.

While the phonological distribution of laryngeals and tone seem exceptional in Itunyoso Trique, Silverman hypothesizes that the phonetic sequencing of the laryngeals, [?] and [h] in such contexts is still preserved so that tone may be recoverable. Since so many tones contrast in an environment where tone could easily be perturbed and non-recoverable, speakers will phase the two so that they do not overlap phonetically. An investigation into the realization of laryngeals in tonal environments, therefore, is pertinent to test this prediction.

\section{Trique Phonetics}

\subsection{Hypothesis and Method}

To determine the degree of tonal overlap that laryngeals show, I examined the pitch perturbation effect of different laryngeals on tone. The prediction a là Silverman is that if tone and laryngeals are staggered, then speakers may still recover the tone on a particular syllable. Such staggering will show a minimal, or very local pitch effect. If however, tone and laryngeals are not phased in this fashion, then there will be a greater pitch effect of the laryngeal on the tone. Furthermore, the realization of $/ \mathrm{T} /$ and $/ \mathrm{h} /$ as a true glottal stop and voiceless fricative is pertinent to their degree of phasing. When $/ R /$ is realized with periods of complete closure and $/ \mathrm{h} /$ with voicelessness, the vocal folds have ceased to vibrate and no pitch can be obtained. Time periods without pitch are evidence of phonetic phasing with respect to vowels carrying pitch for contrastive tone.

Acoustic recordings were obtained from 3-4 native speakers of Itunyoso Trique, where each speaker was asked to repeat words in a carrier sentence: I give $X$ to you; [rikih 1.1 X riãre? 32.1]. Elicited words had different tone and laryngeal combinations. All recordings were made during fieldwork visits to Oaxaca and California in summer-fall, 2005. F0 was calculated as a dynamic curve across $/ \mathrm{V} /$, $/ \mathrm{Vh} /, / \mathrm{V} 1 /, / \mathrm{V} \mathrm{V} /$, and /VPVh/ environments, with 12 pitch points calculated across each of these contexts but 6 pitch points on the vowel preceding [?] (adjusting for shorter duration). Acoustic analysis was done using Praat 4.3 (Boersma and Weenink, 2006) and the R-statistical computing software. 


\subsection{Observations and Analysis}

Three contexts were analyzed in this study: the realization of coda / $/$ /, the realization of coda $/ \mathrm{h} /$, and the realization of $/ \mathrm{V} ? \mathrm{~V}(\mathrm{~h}) /$ sequences. For the purposes of this talk, we will limit our investigation to the context of tone $/ 3 /$. We first consider the realization of root-final coda [?]. Coda glottal stops are usually realized with periods of complete glottal closure, lasting approximately between $80-110$ msec. A spectrogram showing the realization of the word [kka?] 3 'candle' in context is given in (5).

(5) Realization of Coda [?] in Context

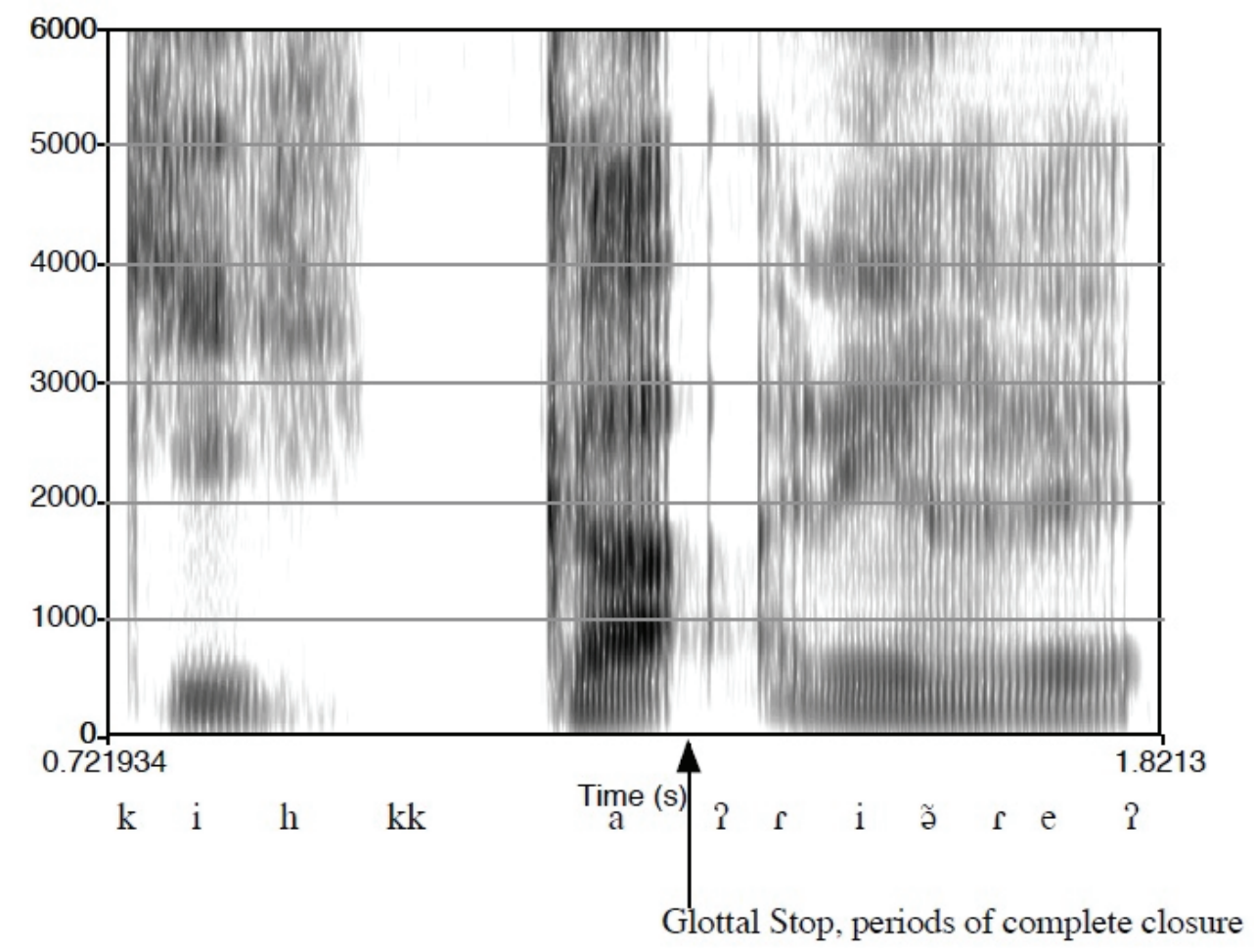




\section{Christian DiCanio}

(6) Coda Glottal Stop Pitch Perturbation

a. Tone $/ 3 /+$ Coda [?]

Tone $3+[?]$ across 3 speakers

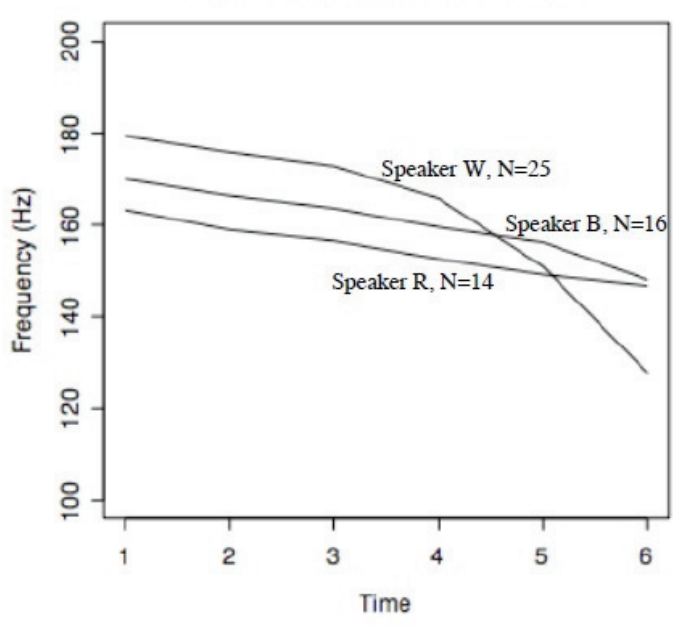

b. Tone /3/ without [?] Coda

Level 3 tone across 3 speakers

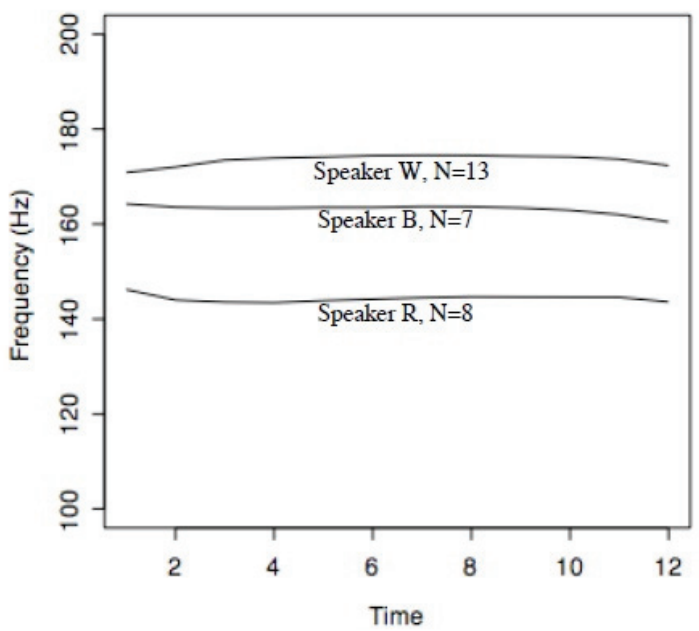

In (5), we notice that there is a duration of complete glottal closure, with one (irregular) glottal pulse in the middle. There are a few irregular glottal pulses preceding the complete closure of the vocal folds (creak). Otherwise, it appears that the glottal stop is realized with almost complete voicelessness, which is typical for Itunyoso Trique. The glottal stop is staggered relative to the modal vowel portion which carries tone. However, there is a noticeable effect of the glottal stop on the pitch of the preceding vowel, shown in (6). While some of the pitch perturbation (especially the fall from time index 1-2) shown in (6a) can be attributed to the presence of voiceless consonant onsets, pitch continues to fall for all speakers across the vowel duration preceding the glottal stop. By contrast, a tone /3/ without a [?] coda is very level, as shown in (6b). The magnitude of the pitch perturbation in (6a) varies by speaker, but is between $16-50 \mathrm{~Hz}$. For speaker W, a large magnitude fall in F0 occurs across approximately $40 \mathrm{msec}$ preceding the glottal stop. Despite its phasing, coda [?] affects pitch across a large duration of the preceding, albeit short, vowel.

In contrast to coda [?], coda $/ \mathrm{h} /$ rarely involves voicelessness. It is regularly realized with breathy phonation, concentrated toward the end of the rime on which it occurs. This is indicated in the spectrogram in (7) by broadband spectral energy after the more modally-phonated vowel. In the example below, the word [t tuttah] 3.3 'deer' appears. 


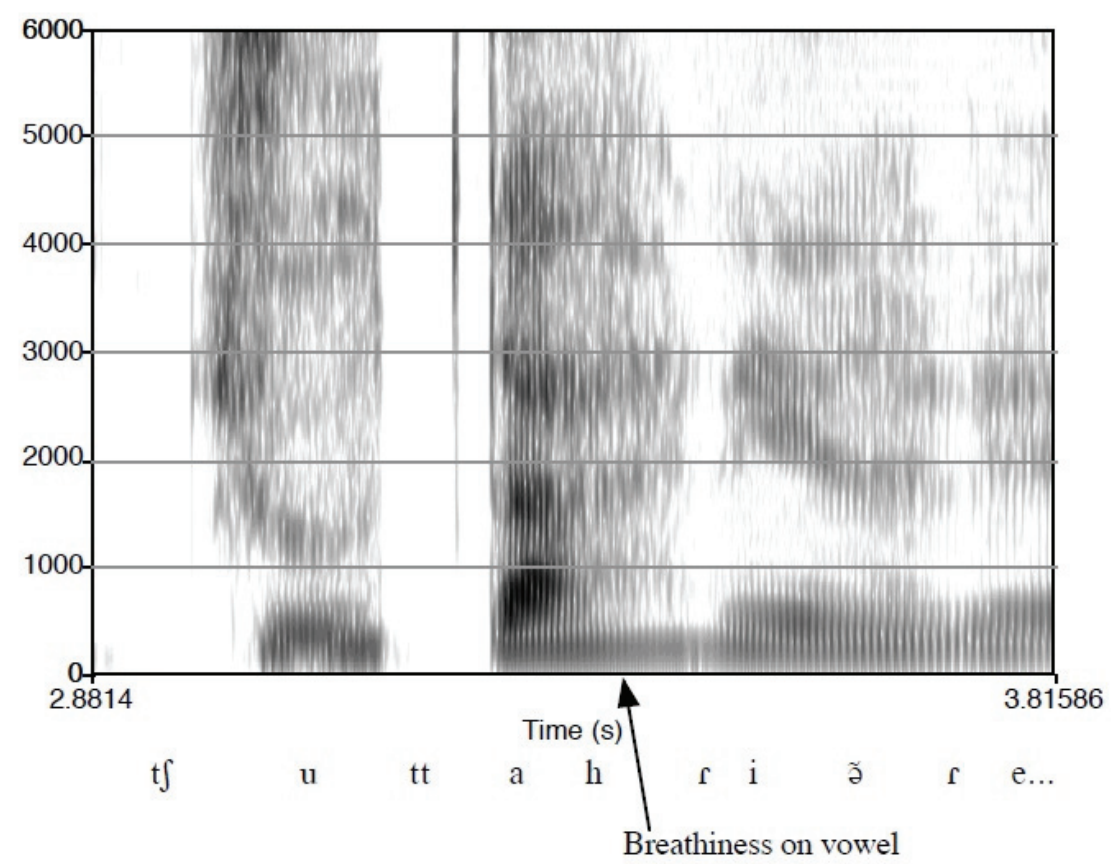

We notice in (7) that there is voicing throughout the rime /ah/. The formants in the latter part of the rime have a largely reduced amplitude though, consisting of increased aperiodic energy occupying the higher frequencies of the spectrum. This is typical for breathy phonation (Ní Chasaide and Gobl 1997, Gordon and Ladefoged 2001). In the data above, it is not possible to distinguish a moment where breathiness is phased relative to the modal portion of the vowel. Rather, it seems to increase gradually throughout the rime duration, where pitch also gradually falls. Plots of the pitch perturbation are shown in (8). 


\section{Christian DiCanio}

(8) Coda $/ \mathrm{h} /$ Pitch Perturbation

a. Tone $/ 3 /+$ Coda $[\mathrm{h}]$

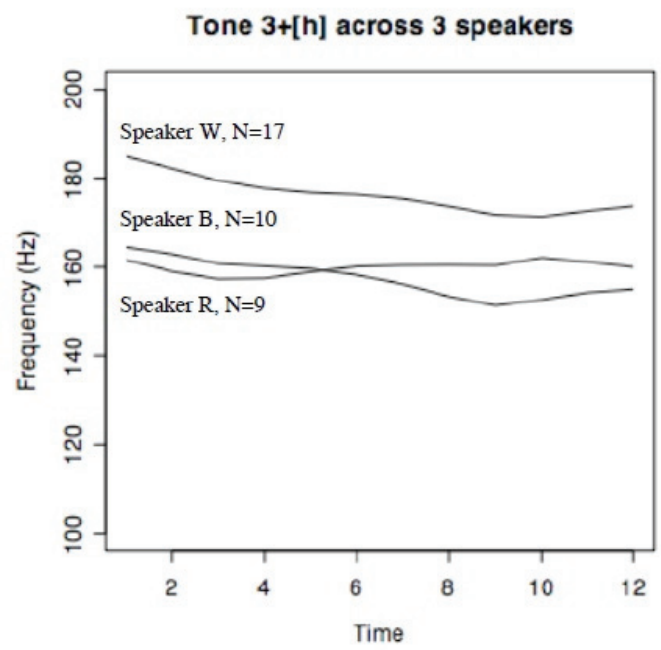

b. Speaker R's Data

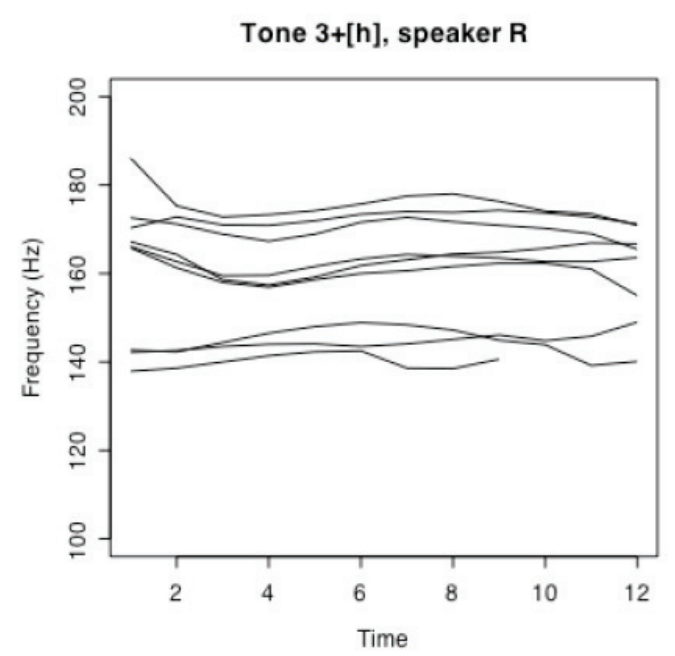

In (8a), for two of the speakers there is a gradual pitch fall across the entire rime duration. For one speaker (R), there is a slight pitch raising. This behavior, however, reflects pitch-raising that occurred on 3 repetitions. In (8b) we notice that the trend appears to be a falling pitch for this speaker, which is timed later for speaker $\mathrm{R}$ than for the other speakers; toward the end of the rime. There is less pitch declination with coda [h] than with coda [?] in Itunyoso Trique. The magnitude of the pitch declination in coda [h] contexts was between $2-13 \mathrm{~Hz}$., where speakers $\mathrm{W}$ and $\mathrm{B}$ both showed a pitch declination of around $13 \mathrm{~Hz}$. The important finding here is the timing of the pitch declination, as it occurs throughout the duration of the rime. It is not timed toward the endpoint for all speakers. Even if we adjust for the increased pitch in the first few time indices in (8a), due to the presence of a voiceless onset, we still observe pitch declination across the vowel. Coda $/ \mathrm{h} /$ is not phased to avoid tonal overlap, but seems to affect pitch across the preceding "modal" vowel.

Finally, we turn our attention to the phonetic manifestation of intervocalic [?], which is normally realized with very slight creak, pitch declination, and amplitude perturbation. There is no complete glottal closure, like we observed for coda [?], a fact which corresponds to findings on Coatzospan Mixtec, a related language (Gerfen and Baker 2005). A spectrogram of the intervocalic glottal stop is given in (9), with the word [гว̃?ə] 3.3 'mushroom.' We notice longer glottal pulses which are associated with the realization of [?]. This is a typical realization of / / in intervocalic position. 
(9) Realization of Intervocalic [?] in Context

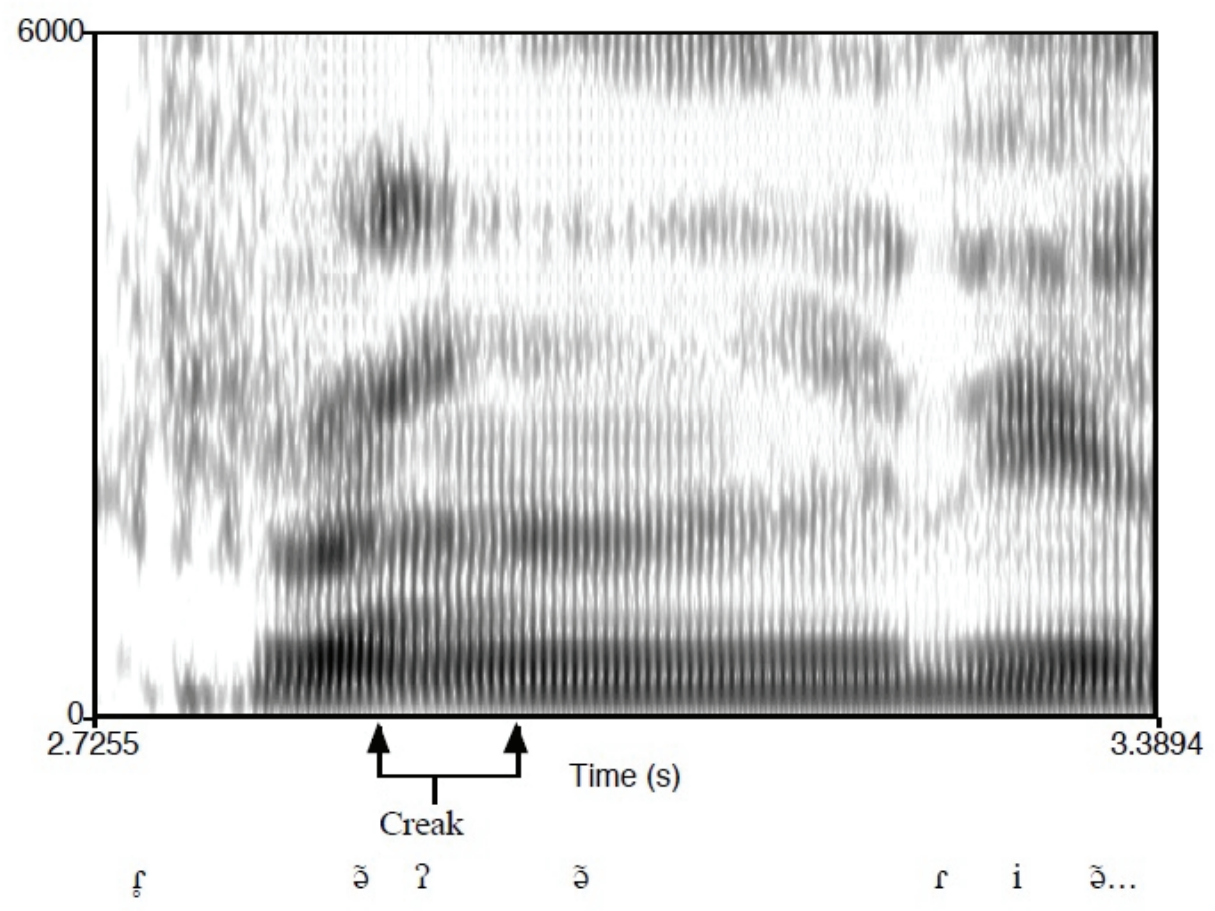

(10) Intervocalic [?] Pitch Perturbation
a. Tone $/ 3 /, / \mathrm{V}$ ? $/$
b. Tone $/ 3 /, / \mathrm{V}$ Ph/

VQV Sequences, tone 3, across 4 speakers

VQVh Sequences, tone 3, across 4 speakers
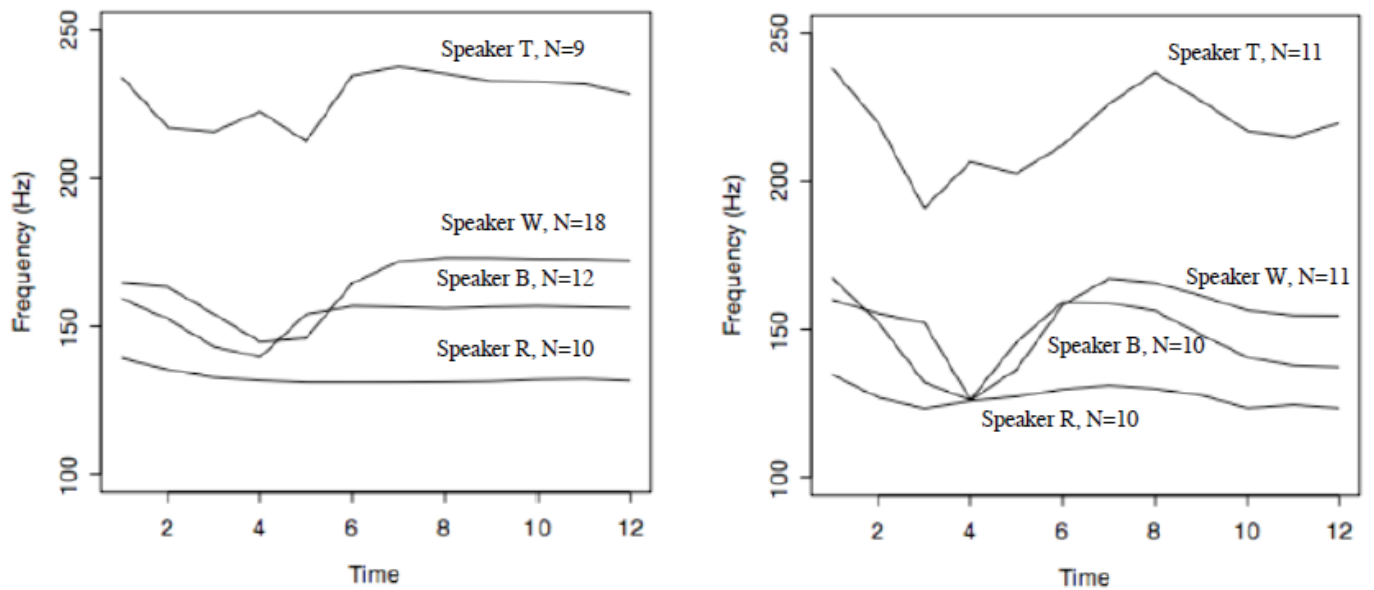

The period of slight creak and pitch perturbation lasts for $1 / 4-1 / 3$ on the duration of $V ? V / V ? V h$ sequences (between 40-80 msec.). In (9), we see that the vowel 


\section{Christian DiCanio}

following the glottalization has a longer duration than the one preceding it, which is attributed to root-final vowel lengthening. If the $/ \mathrm{R} /$ were phased to avoid overlap with the tone on the word, we would not expect it to surface as slight creak, but with periods of complete glottal closure. In (10) we observe the glottal stop perturbing pitch on the surrounding vowels. In (10a) and (10b), the vowel preceding the glottalization has substantially lowered pitch. The vowel following the [?] is level on $V ? V$ sequences, but falls again on $V ? V h$ sequences due to the presence of coda breathiness. The pitch declination observed from the intervocalic glottal stop has a magnitude between $8-47 \mathrm{~Hz}$. Speaker $\mathrm{R}$ realizes $V ? V$ sequences with overall lower pitch than observed with the non-laryngealized tone $/ 3 /$.

From this data, it appears that intervocalic glottalization is not timed so as to avoid pitch overlap. In many cases the pitch perturbation is the main acoustic correlate of the laryngeal, where creak is slight or absent. Furthermore, both coda [h] and [?] are normally realized with some degree of pitch perturbation on the preceding vowel, regardless of whether or not they are realized discretely by long periods of voicelessness. For a coda [?], there is a long period of complete glottal closure while for a coda $[\mathrm{h}]$, there is breathy phonation on the vowel.

Pitch modification due to laryngeals overlaps pitch indicating syllabic tone in Itunyoso Trique. Since it is apparent that speakers do not time laryngeals to avoid such overlap, then how do speakers distinguish the tone on these laryngeallymodified vowels? I suggest that speakers may be sensitive to distinguishing global pitch contours and levels from pitch perturbations that are correlated with laryngeals. For instance, as we observed in (10), the presence of a pitch perturbation for $1 / 3$ of the $V ? V$ duration is distinct from the global pitch level found in these sequences. Additionally, the presence of non-modal phonation-induced pitch declination is distinct from pitch declination with modal phonation. Modal falling tones are distinct from tones that have perturbation due to laryngeals. The phonetic manifestation of laryngeally-perturbed pitch is different in global pitch level and slope from both level and contour tones.

\section{Discussion and Conclusion}

Itunyoso Trique has a large set of tonal and laryngeal contrasts, which are best understood via the language's system of root-final syllable prominence. This position in the word licenses a large set of laryngeal, segmental, and tonal contrasts and is the locus of vowel-lengthening. Prosodic licensing explains the distinct phonological patterning of laryngeals in Itunyoso Trique. This finding jibes well with research on laryngeal patterning in other languages, like Kashaya and Yowlumne (Howe and Pulleyblank 2001). With respect to phonetics, coda glottal stops regularly have long periods of complete glottal closure, making them distinct from intervocalic glottal stops, which are realized with slight creak and pitch perturbations. Coda $/ \mathrm{h} /$ is regularly realized with voicing [h], which overlaps as breathy phonation on the preceding vowel. The phonetic realization of all these contrasts involves pitch perturbations which extend onto the surrounding vowels. Laryngeally-induced pitch perturbation in complex tone languages is problematic 
for a theory of the phonetics-phonology interface where perceptually-optimal positions for laryngeals are directly encoded into the language's phonology. Rather, such patterns suggest that the phonetic manifestation of laryngeals is best understood via language-particular phonetics, where speakers distinguish local and laryngeally-derived pitch perturbations from lexical tone.

\section{References}

Blankenship, Barbara. 2002. The Timing of Nonmodal Phonation in Vowels. Journal of Phonetics, 30:163-191.

Buckley, Eugene. 1994. Theoretical Aspects of Kashaya Phonology andMorphology. Stanford, CSLI.

Buckley, Eugene. 1995. Optimal Imbs in Kashaya. ms. University of Pennsylvania.

Gerfen, Chip, and Kirk Baker. 2005 The Production and Perception of Laryngealized Vowels in Coatzospan Mixtec. Journal of Phonetics 33: 311-334.

Gordon, Matthew, and Peter Ladefoged. 2001. Phonation Types: A CrossLinguistic Overview. Journal of Phonetics 29:383-406.

Hayes, Bruce and Donca Steriade. 2004. Introduction: the phonetic bases of phonological markedness. In Hayes, B., Kirchner, R. and Steriade, D. (eds.) Phonetically based phonology. Cambridge: Cambridge University Press. 1-33.

Hinton, Leanne. 1992. An Accentual Analysis of tone in Chalcatongo Mixtec. Occasional Papers in Linguistics 16, James E. Redden (ed.) 173-82. Carbondale. Southern Illinois University.

Hollenbach, Barbara. 1984. The Phonology and Morphology of tone and laryngeals in Copala Trique. Phd Dissertation. University of Arizona.

Howe, Darin, and Douglas Pulleyblank. 2001. Patterns and Timing of Glottalization. Phonology 18: 45-80.

Longacre, Robert. 1952. Five Phonemic Pitch Levels in Trique. Acta Linguistica 7: $62-81$.

Longacre, Robert. 1957. Proto-Mixtecan. Folklore and Linguistics Memoir 5, vii. Indiana University Research Center in Anthropology, Bloomington. Indiana University.

Macaulay, Monica and Joseph C. Salmons. 1995. The Phonology of Glottalization in Mixtec, International Journal of American Linguistics 61(1): 38-61.

Ní Chasaide, A, and Gobl, C. 1997. Voice Source Variation. In The Handbook of Phonetic Sciences:427-461. William Hardcastle, and John Laver (eds.). Cambridge, MA. Blackwell

Silverman, Daniel. 1997a. Phasing and Recoverability, Phd Dissertation, Garland.

Silverman, Daniel. 1997b. Laryngeal Complexity in Otomanguean Vowels. Phonology 14: 235-261. 


\title{
Christian DiCanio
}

Steriade, Donca. 2001. Directional Asymmetries in Place Assimilation. In The Role of Speech Perception in Phonology. Elizabeth Hume and Keith Johnson (eds). Academic Press.

Zhang, Jie. 2001. The Effects of Duration and Sonority on Contour Tone Distribution: Typological Survey and Formal Analysis, PhD Dissertation, UCLA.

\author{
Christian DiCanio \\ Dynamique du Langage \\ Université Lyon 2 (Lumière) \\ 214C, L'institut de sciences de l'homme \\ Lyon, France 69363 \\ cdicanio@gmail.com
}

